\title{
Transcranial Doppler ultrasonography (uses, limitations, and potentials): a review article
}

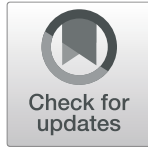

Mohammed F.A Ali®D

\begin{abstract}
Background: The additional information that transcranial Doppler can provide as part of a multimodal imaging protocol in many clinical settings has not been evaluated.

Main body: Transcranial Doppler is a bedside procedure used to assess cerebral blood flow velocity via cerebral circulation and pulsatility index (PI). Many diseases can lead to cerebral vessels vasospasm as in subarachnoid hemorrhage and trauma. Cerebral vessels vasospasm represented by abnormal elevation of cerebral blood flow velocity. Intracranial pressure can be monitored by pulsatility index which reflects blood flow resistance in cerebral vessels. Transcranial Doppler ultrasonography is also the unique modality for detection of micro emboli in high-risk patients. Also, it can be used for evaluation of circulatory arrest with subsequent confirmation of brain death

Conclusion: Transcranial Doppler ultrasonography is the only diagnostic modality that provides a reliable assessment of cerebral blood flow patterns in real time. The physiological information obtained from TCD is complementary to the anatomical details obtained from other neuroimaging modalities. TCD is relatively cheap, can be performed bedside, and allows monitoring in acute emergency settings.
\end{abstract}

Keywords: Transcranial Doppler, Cerebral vasospasm, Subarachnoid hemorrhage, Ischemic stroke, Arteriovenous malformation, Traumatic brain injury

\section{Background}

Transcranial Doppler ultrasonography (TCD) was first introduced on clinical practice in 1986. Since TCD was extensively used in outpatient, intraoperative, and critical care units. TCD represents bedside, noninvasive, cheapest, easy repetitive modality which became widely used in patients with cerebrovascular diseases $[1,2]$. It provides information about of brain hemodynamics in real time. Repetitive TCD monitoring may recognize recanalization during antifibrinolytic therapy for acute ischemic stroke [3].

This article describes the important clinical role of TCD in neuro surgical practice as in monitoring of patients with post-aneurysmal subarachnoid hemorrhage vasospasm, patient with ischemic stroke, and traumatic brain injury (TBI) [4]. Other clinical applications are arteriovenous malformation (AVM), diagnosis of brain

Correspondence: dr.mohamedfathy2006@gmail.com

Faculty of Medicine, Cairo University, 6 Sray El Manial, Cairo, Egypt death, detection of emboli and in parenchymal brain disease. Also, it has crucial role in carotid endarterectomy for diagnosis of hyper perfusion syndrome and prevention of its sequalae $[5,6]$.

\section{Main text}

Transcranial Doppler basic concepts

Procedure of TCD involves the placement of electrical probe of range gated ultrasonography permitting assessment of blood flow velocity in the cerebral arteries. At low frequencies $(2 \mathrm{MHz})$ soft tissues and bone attenuation is low compared with high frequencies, thus providing accurate recoding of cerebral blood flow velocity (CBFV) [7, 8].

The ultrasonic beam that emitted from TCD probe crosses the skull at the target location and reflected from the erythrocytes which flow at different speeds in the cerebral vessels and the resultant signals are recorded [9]. 
Table 1 Mean cerebral blood flow velocities (cm/s) based on age groups [5]

\begin{tabular}{llll}
\hline Artery & Age $\mathbf{2 0 - 4 0}$ years & Age $\mathbf{4 0 - 6 0}$ years & Age $>\mathbf{6 0}$ years \\
\hline Anterior cerebral artery & $56-60$ & $53-61$ & $44-51$ \\
Middle cerebral artery & $74-81$ & $72-73$ & $58-59$ \\
Posterior cerebral artery (PCA) (P1) & $48-57$ & $41-56$ & $37-47$ \\
PCA (P2) & $43-51$ & $40-57$ & $37-47$ \\
Vertebral artery & $37-51$ & $29-50$ & $30-37$ \\
Basilar artery & $39-58$ & $27-56$ & $29-47$ \\
\hline
\end{tabular}

The difference between the transmitted and received signals is known as the Doppler shift. The time interval between pulse emission to pulse reception determines the depth from which the Doppler shift obtained [9-11]. Mean CBFV is calculated using a spectral envelope (also known as fast Fourier transformation) Mean CBFV 5 $[\mathrm{PSV}+(\mathrm{EDV} \times 2)] / 3$, where PSV is peak systolic CBFV and EDV is end-diastolic CBFV $[9,12]$.

The basic principle of TCD ultrasonography is based that the CBFV in a cerebral artery is inversely proportional to the diameter of that artery. Thus, transcranial ultrasonography provides an indirect assessment of cerebral vessels diameter through calculating the Doppler shift. Also, TCD can assess PSV and EDV and by the use of these values, we can calculate CBFV (Tabl e1), pulsatility index (PI), and resistant index (RI) [6, 12-14]. Cerebral blood flow velocity is usually affected by some physiological factors as age, gender, hematocrit value, presence of fever, metabolic factor, and diameter of blood vessel [15].

The pulsatility index (PI) and resistant index (RI) are calculated from TCD parameters as follows: PI (PSV$\mathrm{EDV}) /$ mean CBFV and RI (PSV-EDV)/PSV (Table 2). The pulsatility index is an indicator of amount of vascular resistance in distal intracranial pressure and it is used as indirect evaluation of intracranial pressure when ICP exceeding $20 \mathrm{mmHg}$. It is also found that there is a good correlation between ICP and RI but this correlation is less sensitive than IP $[6,16]$.

In isolation of intracranial arteries, the first concern is to determine the site (window) where the ultrasound $d$ wave can penetrate the skull to evaluate the cerebral arteries (Fig. 1). To assess intracranial arteries, there are three windows through which the ultrasound waves pass through. Transtemporal window (between the eye and ear pinna) to assess the middle cerebral artery often presents at $30-60 \mathrm{~mm}$ depth from the skull surface while anterior cerebral artery at depth $65-80 \mathrm{~mm}$ with the probe placed in anterosuperior position and internal carotid artery at depth $55-70 \mathrm{~mm}$ with the probe placed in poster-inferior position. Second window is the transorbital window to assess the opthalmic artery. Third window is the transforaminal window (across the foramen magnum) to evaluate vertebral arteries [15-17].

\section{Role of transcranial Doppler in cerebral vasospasm}

Vasospasm of intracranial blood vessels is defined as a transient narrowing of cerebral arteries that may lead to transient or permeant neurological dysfunctions. It can occur in many CNS (central nervous system) disorders; the most common one is following of spontaneous subarachnoid hemorrhage (SAH) due to rupture of cerebral aneurysm. Other disorders include trauma, preeclampsia, and meningitis, but the course of vasospasm in these conditions is usually milder [18-21].

Vasospasm due to aneurysmal SAH is usually initiated between 3rd and 5th day after hemorrhage and gradually declining after the 14th day, and it is the most common cause of morbidity and mortality in aneurysmal SAH. The pathogenesis of this phenomena is not well understood, and it is hypothesized that blood extravasated from SAH hemorrhage initiates complex cellular mechanisms that may lead to vascular smooth muscle contraction [18, 20, 22].

Cerebral digital subtraction angiography remains the most important diagnostic tool for vasospasm but it is invasive, associated with significant morbidity, and not as feasible as bedside tool. Thus, TCD is noninvasive bedside tool and can detect vasospasm at earlier stages before it become clinically manifested and can be used

Table 2 Normal pulsatility index (mean \pm SD) based on age groups [5]

\begin{tabular}{llll}
\hline Artery & Age $\mathbf{2 0 - 4 0}$ years & Age $\mathbf{4 0 - 6 0}$ years & Age $\mathbf{4 0 - 6 0}$ years \\
\hline Anterior cerebral artery & $0.80 \pm 0.14$ & $0.85 \pm 0.16$ & $0.85 \pm 0.16$ \\
Middle cerebral artery & $0.83 \pm 0.14$ & $0.82 \pm 0.13$ & $0.82 \pm 0.13$ \\
Posterior cerebral artery & $0.76 \pm 0.12$ & $0.79 \pm 0.12$ & $0.79 \pm 0.12$ \\
Vertebral artery & $0.82 \pm 0.03$ & $0.78 \pm 0.04$ & $0.78 \pm 0.04$ \\
Basilar artery & $0.81 \pm 0.05$ & $0.78 \pm 0.05$ & $0.78 \pm 0.05$ \\
\hline
\end{tabular}


Table 3 Ranges of sensitivity and specificity of transcranial Doppler ultrasonography to detect vasospasm in different arteries [5]

\begin{tabular}{lll}
\hline Vessels & Sensitivity (\%) & Specificity (\%) \\
\hline Internal carotid artery C1 segment & 100 & 91 \\
Anterior cerebral artery A1 segment & $13-82$ & $65-100$ \\
Middle cerebral artery M1 segment & $38-91$ & $94-100$ \\
Posterior cerebral artery P1 segment & 48 & 69 \\
Vertebral artery & 43.8 & 88 \\
Basilar artery & $73-76.9$ & 79 \\
\hline
\end{tabular}

during and after aneurysmal surgery [23, 24]. Also, TCD can be daily repeated for monitoring of progression of vasospasm and efficacy of treatment [25].

Many studies recommended daily monitoring of patients with aneurysmal SAH with high risk for developing of vasospasm for early detection of vasospasm before it becomes clinically manifested and introducing of early management either by triple $\mathrm{H}$ therapy or endovascular procedures $[15,17,26]$.

The sensitivity of transcranial Doppler in detecting of vasospasm is high in middle cerebral artery (75 to $90 \%$ ), also in vertebral and basilar arteries (77\%), but its sensitivity is low in detecting anterior cerebral artery vasospasm (15\%) due to its collateral pattern of flow (Table 3) [2, 17].

\section{TCD in predicting vasospasm}

Generally, increasing in mean cerebral blood flow velocity (CBFV) is an indicator of vasospasm in major cerebral vessels. Some studies found that low pulsatility index (PI) is another indicator of vasospasm $[2,6]$.

In middle cerebral artery vasospasm (MCA), several studies suggest a correlation between MCA FVm and severity degree of vasospasm. Mild vasospasm $(\mathrm{FVm}<120$ $\mathrm{cm} \mathrm{s}^{-1}$ ), moderate vasospasm ( $\mathrm{FVm}$ ranges from $\geq 120$ $\mathrm{cm} \mathrm{s}^{-1}$ to $<200 \mathrm{~cm} \mathrm{~s}^{-1}$ ), and severe vasospasm (FVm > $200 \mathrm{~cm} \mathrm{~s}^{-1} \mathrm{c}$ ). These spikes in FVm can be detected via TCD up to 2 days before the occurrence of symptoms onset with high sensitivity and specificity $[25,26]$.

In basilar artery (BA) vasospasm, some studies found that CBFV ratio between $\mathrm{BA}$ and extracranial vertebral artery correlates strongly with BA narrowing. A ratio MRE than 3.0 with BA flow velocity greater than $85 \mathrm{~cm} /$ $\mathrm{s}$ is usually associated with $92 \%$ sensitivity and $97 \%$ specificity for BA narrowing [26-28].

\section{The role of TCD in the evaluation of acute stroke}

Transcranial Doppler (TCD) is one of the most useful tools in diagnosis of acute ischemic stroke. It provides valuable information about micro emboli, degree of cerebral vessel stenosis, and collateral flow. TCD can detect acute occlusion of middle cerebral artery with sensitivity more than $90 \%$ (Fig. 2) [29-31].

TCD has a prognostic value in acute ischemic stroke. Complete cerebral occlusion detected by TCD is usually associated with poor functional outcome, disability, and even death while normal parameters are associated with good outcome with early recovery from stroke. Detection of occlusion of M1 segment of middle cerebral artery within $6 \mathrm{~h}$ from stroke onset by TCD may be

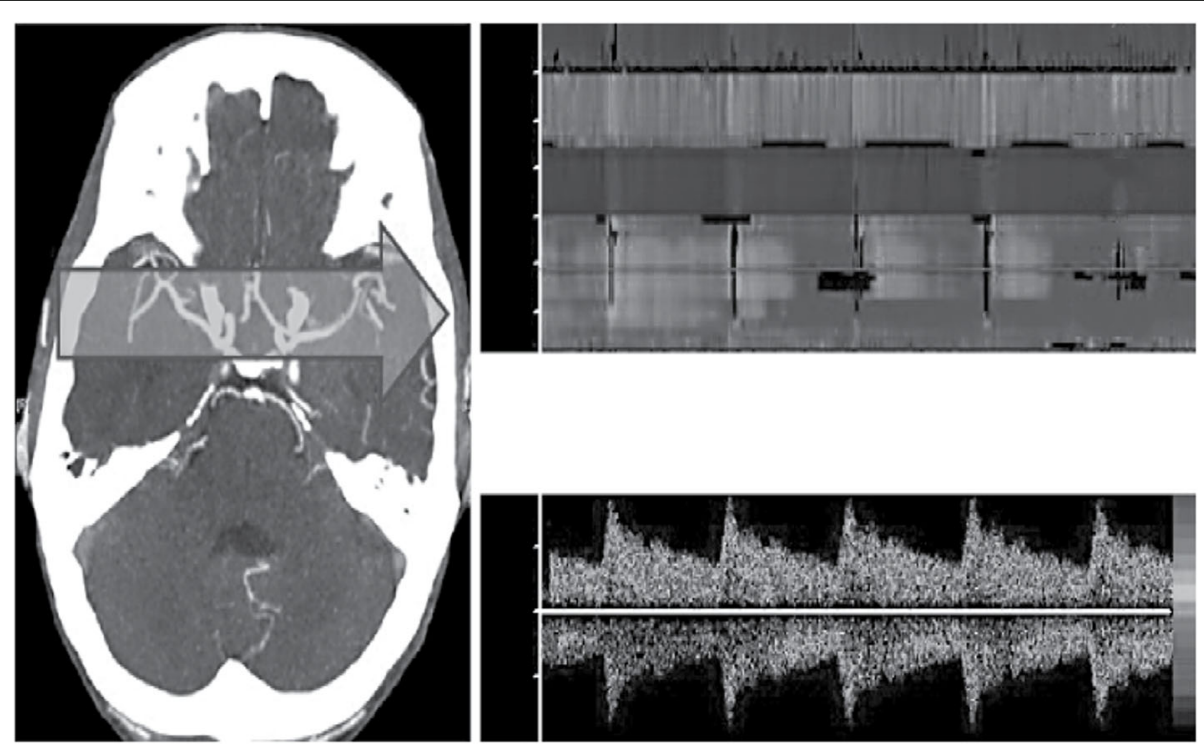

Fig. 1 Transcranial insolation of anterior circulation. Power-mode multigated transcranial Doppler (TCD) employs $2 \mathrm{MHz}$ ultrasound that penetrates the entire diameter of the skull (a). In an average adult skull, midline is believed to be at $75 \mathrm{~mm}$. Thus, the flow signals obtained from beyond $75 \mathrm{~mm}$ are from contralateral arteries [6]. 


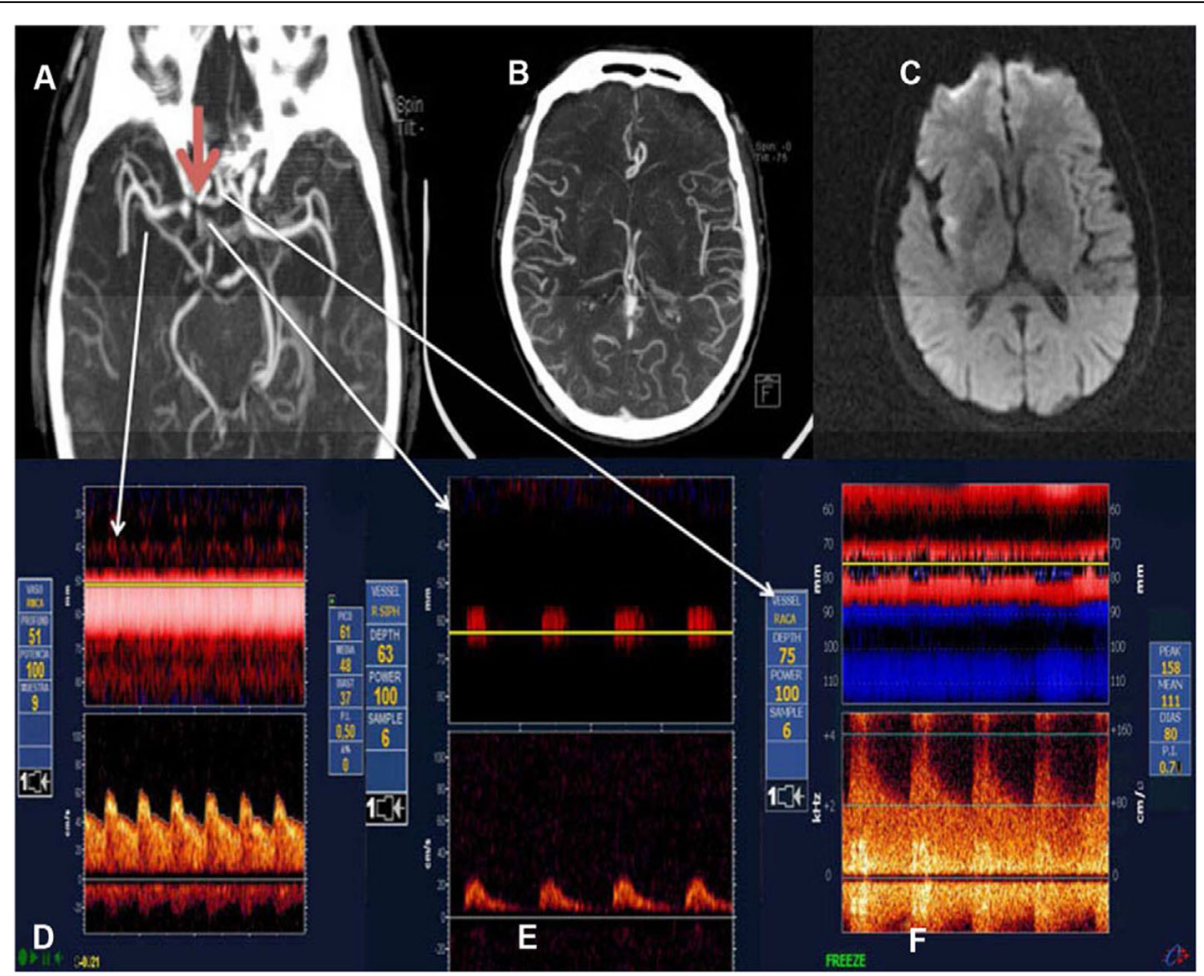

Fig. 2 Case 19: 78-year-old male, arrived within 30 min of symptom onset of a right-side MCA stroke. Initial NIHSS score of 2 points. a CTA interpreted as normal by the neuroradiologist on call; the red arrow demonstrates a short right terminal carotid occlusion. b CTA demonstrates symmetrical filling of both MCA territories, which may be due to collateral flow. c DWI showing small insular ischemic changes. $\mathbf{d}$ TCD at the beginning of thrombolysis demonstrates a middle cerebral artery with good flow velocity but with low pulsatility index suggesting post-stenotic flow and a proximal vascular lesion. e Occlusion of right terminal carotid as revealed by the TCD. $\mathbf{f}$ Inverted, high velocity flow in the right anterior cerebral artery compatible with anterior cross filling (collateral flow) [33]

associated with hemorrhagic transformation in the infarcted area [29, 32, 33].

Patients with sickle cell anemia have high risk of developing ischemic stroke which can be prevented by chronic blood transfusion. TCD is used for screening of these children and identify of those who have risk for developing stroke [29, 34].

After initiation of the treatment protocol of ischemic stroke, recanalization starts to occur. TCD is used to monitor the effectiveness of treatment, adjustment of doses, and duration particularly with antifibrinolytic agents as recanalization occurs rapidly [30,35]

\section{Role of TCD in emboli monitoring}

TCD ultrasound is considered as the only available model for detection of micro emboli in real time within cerebral arteries. Micro emboli have high-intensity signal in TCD ultrasound and has characteristic acoustic impendence, and it can be distinguished easily from erythrocytes that flow simultaneously $[1,36]$.

Detection of asymptomatic emboli by TCD is crucial in patients whom at high risk for development of cerebral stroke, e.g., carotid artery stenosis, atrial fibrillation, prosthetic cardiac valve, cardiomyopathy, endocarditis, and carotid endarterectomy [11,37].

Screening of patients of ischemic stroke and patients with significant carotid occlusion by TCD is helpful in evaluation of degree of cerebral embolization, thus will be reflected in their management strategy $[36,37]$.

\section{Role of transcranial Doppler in assessment and} management of cerebral arteriovenous malformations Arteriovenous malformations (AVMs) are congenital anomalies of the cerebral blood vessels characterized by presence of direct connection between arteries and veins, with an absence of arterioles and capillaries. They are usually presented with intracranial hemorrhage, convulsions, or both [38-40].

After treatment of AVM, the former feeder arteries usually exhibit reduction in the mean velocity and elevation of arterial pressure that may led to intracerebral hemorrhage and venous infarction. These changes vary between patients according to the degree of arteriovenous shunting within the AVM. Because of the importance of the changes and their impact on the neurological condition of the patients, 


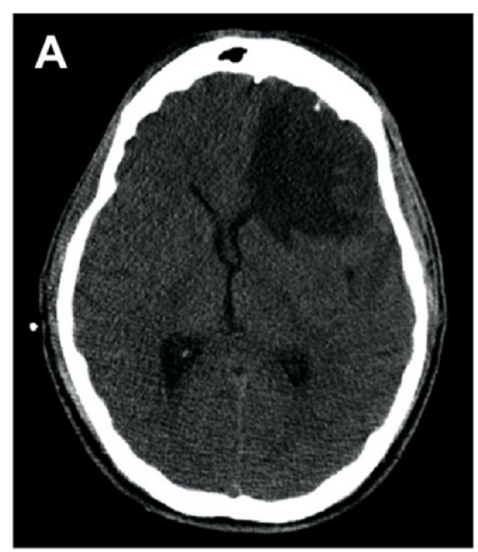

\section{B}

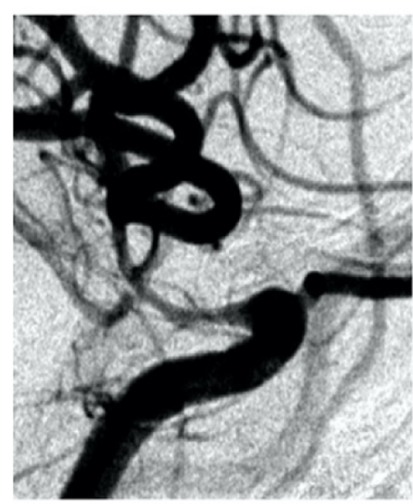

RSIPHN

12:33:09 PM

Depth 72

Power 50

Sample 9

Peak 158

Dias 96

Mean 120

P.I. 0.51

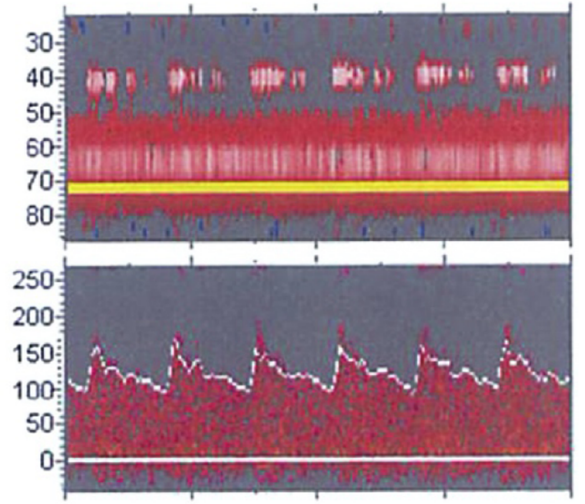

\section{C}
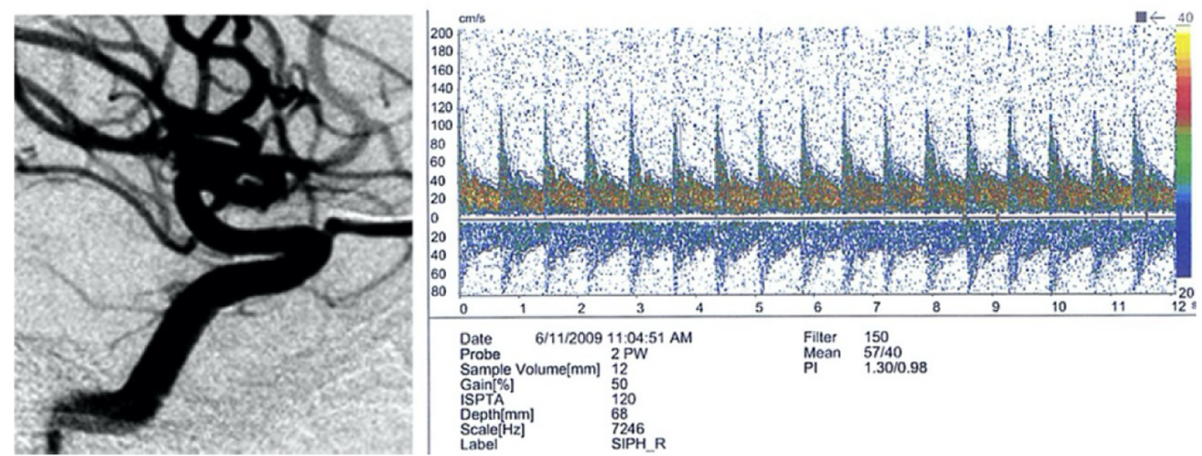

Fig. 3 Patient with right side contusion. a CT scan demonstrating contusion. b Right common carotid artery injection showing severe vasospasm affecting right carotid siphon before angioplasty and corresponding TCD measured CBFV in the right carotid siphon. $\mathbf{c}$ Resolution of vasospasm after transluminal angioplasty and TCD showed CBFV normalization after angioplasty [5]

these changes should be assessed by noninvasive bed side TCD [39-42].

\section{Assessment of AVM using TCD}

AVMs are often supplied by distinct high-flow shunts and are characterized by decreased or absence of vasomotor reactivity. These features make it possible for TCD to differentiate AVM feeding arteries from healthy cerebral vessels, and specificity of TCD has high sensitivity in detection of medium-sized and large AVMs, but its sensitivity decreases in detection of AVM less than $2.5 \mathrm{~cm} \mathrm{[43].}$

The most commonly used TCD parameters in evaluation of basal cerebral arteries and those of AVM are velocity and pulsatility index (PI). By using these parameters, AVM feeding arteries are characterized by the presence of high velocity and low PI. So, we can differentiate between them and normal cerebral arteries. Most of studies concluded that the AVM size affects velocity and PI measurements. In large AVM, there is an 
increase in mean velocity and diminish in PI with progressive increase in volume of AVM $[39,44]$.

\section{TCD assessment following AVM intervention}

TCD evaluation of AVM after intervention either by surgical resection or embolization revealed a reduction in mean flow velocity and an increase in PI in the former feeding arteries when compared to preoperative values. Firstly, normalization of PI occurs over the first few days after intervention while normalization of mean velocity takes much longer (1-3 weeks) [45].

A study by Petty et al. compared TCD parameter changes following surgical resection with embolization. They found that there was dramatic change in mean velocity and PI in surgically treated group [41].

In embolization, different results may emerge depend on whether the embolization is partial or staged. In first and subsequent stages of staged embolization, there is an increase in the mean velocity of the feeding artery. Thus, it may be due to increase in collateral flow, absence of diameter reduction, or due to recanalization of previously canalized feeders [38].

The changes in TCD parameters with the use of radiosurgery in AVM occur more gradually and have of latency period from 1 to 2 years [46].

\section{Role of transcranial Doppler (TCD) in traumatic brain injury (TBI)}

Traumatic brain injury represents a major health problem and a leading cause of death and disability all over the world. As a result of direct trauma, there is disruption of normal brain function leading to primary brain injury and is usually followed by secondary brain injury especially in moderate and severe TBI; it includes cerebral infarction, hydrocephalus, brain edema, raised intracranial pressure, and infection $[47,48]$.

Several methods were used to monitor TBI patients in intensive care unit as monitoring of ICP via interventricular catheter or subdural, intraparenchymal, and subarachnoid probes. Also, brain oxygen extraction in the brain can be evaluated through jugular venous oxygen saturation $[49,50]$.

Transcranial Doppler (TCD) allows a bed side, noninvasive evaluation of monitoring of ICP (measured by pulsatility index (PI) values of the middle cerebral and other cerebral vessels), cerebral blood flow mean (through measurement of mean blood velocity) and cerebral perfusion pressure (CPP). Also, TCD may be used for detection and monitoring of cerebral vasospasm after traumatic SAH (Fig.3) [51, 52]

\section{Role of TCD in carotid endarterectomy}

Carotid endarterectomy is usually associated with perioperative hemodynamic disturbance, e.g., intraoperative hypoperfusion that may lead to brain ischemia or postoperative hyper perfusion that may cause intracerebral hemorrhage [53, 54].

Early postoperative detection of cerebral hyper perfusion can prevent the occurrence of serious complications because lowering of blood pressure helps in prevention of progression of cerebral hyper perfusion $[53,55]$.

Intraoperative assessment of the difference in mean flow velocity of MCA before and after carotid declamping by TCD is the gold standard in detection of cerebral hyper perfusion. An increase of $>100 \%$ in MCA velocity after declamping is usually associated with cerebral hyper perfusion [54, 56].

Recent studies concluded that postoperative assessment of MCA velocity within $2 \mathrm{~h}$ postoperatively and compare it with the preoperative measurement help in detection of cerebral hyper perfusion in up to $41 \%$ of patients [57].

\section{Role of TCD in diagnosis and monitoring of intracranial hypertension and brain death evaluation}

Diagnosis of brain death is an important social and legal issue, and it is usually confirmed by physical examination and some technical modalities such as angiography, EEG, and radionuclide scan. TCD offers some valuable information beside these modalities and can be performed bedside with less time consumed. Transcranial Doppler detects velocity flow and shape of waveform, and differentiate between systolic and diastolic CBFV $[58,59]$.

Progressive increase in intracranial pressure is associated in reduction in diastolic CBFV; when ICP exceed end diastolic blood pressure, CBFV became nil and thus associate with appearance of small systolic spikes followed by absent of flow in both systolic and diastolic direction. With continued presence of this pattern, brain death is confirmed $[59,60]$.

\section{Role of TCD in disease of brain parenchyma and brain tumor}

The use of transcranial ultrasonography in parenchymal brain disease and brain tumors is limited to the neonates because of the presence of open fontanelle help in proper isolation of brain parenchyma [61].

Despite these limitations, transcranial ultrasonography may give some useful information. In Parkinson's disease, the substantia nigra shows increase in echogenicity than in normal individuals. Also, there is a reduction in echogenicity in raphe nuclei in patients with unipolar depression [62, 63].

In high-grade glioma, TCD shows abnormal arterial and venous pattern indicating high vascularity of these tumors; these patterns are absent or mild in low-grade glioma [61, 64]. 


\section{Conclusion}

In the critically ill patients with ischemic sroke, $\mathrm{SAH}$, and TBI in which there are disturbance of cerebral hemodynamics, neuromonitoring should be extended. TCD is noninvasive, repetitive, easily available at the bedside, radiation free, and can help prevent delayed neurologic deficits [6].

The use of TCD helps tools in the early detection of cerebral vasospasm following SAH before it became clinically manifested helping in early incorporation of the specific treatment measure for vasospasm [17].

In patients with hyperacute stroke, TCD helps in detection of ischemic stroke and in monitoring of efficacy of treatment especially with those with arterial occlusion [34].

Also, TCD is very useful in early diagnosis of hyper perfusion syndrome after carotid endarterectomy, confirmation of brain death, and monitoring of AVM after definitive treatment $[6,40]$.

\section{Limitations of the TCD}

Although the presence of many advantages to the use of TCD in intensive care patient's status post-SAH and in many situations mentioned before, there are some limitations of TCD.

- It is highly operator dependent, with the handheld technique requiring detailed three-dimensional knowledge of cerebrovascular anatomy and its variations [6]

- Measurements of velocity may be affected by others factors such as age, gender, hematocrit value, differences in the partial pressure of $\mathrm{CO} 2$ within the blood, and thickness of skull bone [42].

- TCD measurements are also limited to the large basal arteries and can only provide an index of global rather than local cerebral blood flow velocity [42].

- Also, in AVM monitoring by TCD site of AVM can be an obstacle; many studies concluded that superficial AVM and those located in the parietal, occipital, and cerebellar regions are difficult to be detected [40].

\footnotetext{
Abbreviations

TCD: Transcranial Doppler ultrasonography; RI: Resistant Index; CBFV: Cerebral blood flow velocity; ICP: Intracranial pressure; PI: Pulsatility index; MCA: Middle cerebral artery; FVm: Mean flow velocity; BA: Basilar artery; BI: Traumatic brain injury; CNS: Central nervous system; AVM: Arteriovenous malformation; SAH: Subarachnoid hemorrhage; PSV: Peak systolic velocity; CPP: Cerebral perfusion pressure; EDV: End diastolic velocity; CT: Computed tomography; CTA: Computed tomography angiogram; DWI: Diffusionweighted image
}

\section{Acknowledgements}

Not applicable.

\section{Author's contributions}

Mohammed F. A Ali: data interpretation and analysis, and writing the paper. The author(s) read and approved the final manuscript.

\section{Funding}

No funding.

\section{Availability of data and materials}

The datasets and analyzed during the current study are available from the corresponding author on reasonable request.

\section{Declarations}

Ethics approval and consent to participate

Not applicable.

Consent for publication

Not applicable.

\section{Competing interests}

The author declares no competing interests.

Received: 24 November 2020 Accepted: 21 April 2021

Published online: 06 September 2021

References

1. Tsivgoulis G, Sharma VK, Hoover SL, Lao AY, Ardelt AA, Malkoff MD, et al. Applications and advantages of power motion-mode Doppler in acute posterior circulation cerebral ischemia. Stroke. 2008;39(4):1197-204. https:// doi.org/10.1161/STROKEAHA.107.499392.

2. Sharma VK, Tsivgoulis G, Lao AY, Malkoff MD, Alexandrov AV. Noninvasive detection of diffuse intracranial disease. Stroke. 2007;38(12):3175-81. https:// doi.org/10.1161/STROKEAHA.107.490755

3. Saqqur M, Hill MD, Alexandrov AV, Roy J, Schebel M, Krol A, et al. Derivation of power M-mode transcranial doppler criteria for angiographic proven MCA occlusion. J Neuroimaging. 2006;16(4):323-8. https://doi.org/10.1111/j.1 552-6569.2006.00055.x

4. Navarro JC, Lao AY, Sharma VK, Tsivgoulis G, Alexandrov AV. The accuracy of transcranial Doppler in the diagnosis of middle cerebral artery stenosis. Cerebrovasc Dis. 2007;23(5-6):325-30. https://doi.org/10.1159/000099130.

5. Kalanuria A, Nyquist PA, Armonda RA, Razumovsky A. Use of Transcranial Doppler (TCD) ultrasound in the neurocritical care unit. Neurosurg Clin N Am. 2013;24(3):441-56. Available from:. https://doi.org/10.1016/j.nec.2013.02. 005.

6. Sharma VK, Wong KS. Alexandrov A V. Transcranial Doppler. Front Neurol Neurosci. 2016;40:124-40. https://doi.org/10.1159/000448309.

7. Aaslid R, Markwalder TM, Nornes H. Noninvasive transcranial Doppler ultrasound recording of flow velocity in basal cerebral arteries. J Neurosurg. 1982;57(6):769-74. https://doi.org/10.3171/jns.1982.57.6.0769.

8. Aaslid R, Huber P, Nornes H. Evaluation of cerebrovascular spasm with transcranial Doppler ultrasound. J Neurosurg. 1984;60(1):37-41. https://doi. org/10.3171/jns.1984.60.1.0037.

9. Rasulo FA, De Peri E, Lavinio A. Transcranial Doppler ultrasonography in intensive care. Eur J Anaesthesiol. 2008:25(SUPPL. 42):167-73. https://doi. org/10.1017/S0265021507003341

10. White $\mathrm{H}$, Venkatesh B. Applications of transcranial Doppler in the ICU: A review. Intensive Care Med. 2006;32(7):981-94. https://doi.org/10.1007/ s00134-006-0173-y.

11. Moppett IK, Mahajan RP. Transcranial Doppler ultrasonography in anaesthesia and intensive care. Br J Anaesth. 2004;93(5):710-24. https://doi. org/10.1093/bja/aeh205

12. Droste DW, Harders AG, Rastogi E. A transcranial doppler study of blood flow velocity in the middle cerebral arteries performed at rest and during mental activities. Stroke. 1989;20(8):1005-11. https://doi.org/10.1161/01.STR.2 0.8 .1005 .

13. Shahlaie K, Keachie K, Hutchins IM, Rudisill N, Madden LK, Smith KA, et al. Risk factors for posttraumatic vasospasm: Clinical article. J Neurosurg. 2011; 115(3):602-11. https://doi.org/10.3171/2011.5.JNS101667.

14. Bellner J, Romner B, Reinstrup P, Kristiansson KA, Ryding E, Brandt L. Transcranial Doppler sonography pulsatility index (PI) reflects intracranial 
pressure (ICP). Surg Neurol. 2004;62(1):45-51. https://doi.org/10.1016/j. surneu.2003.12.007.

15. Sarkar S, Ghosh S, Ghosh SK, Collier A. Role of transcranial Doppler ultrasonography in stroke. Postgrad Med J. 2007;83(985):683-9. https://doi. org/10.1136/pgmj.2007.058602.

16. Kumar G, Alexandrov AV. Vasospasm surveillance with transcranial Doppler sonography in subarachnoid hemorrhage. J Ultrasound Med. 2015;34(8): 1345-50. https://doi.org/10.7863/ultra.34.8.1345.

17. Ekelund A, Säveland H, Romner B, Brandt L. Is transcranial Doppler sonography useful in detecting late cerebral ischaemia after aneurysmal subarachnoid haemorrhage? Br J Neurosurg. 1996;10(1):19-25. https://doi. org/10.1080/bjn.10.1.19.

18. RigamontiA, Ackery A, Baker AJ. Transcranial Doppler monitoring insubarachnoid hemorrhage: a critical tool in critical care. Can JAnaesth. 2008;55(2):112-23. https://doi.org/10.1007/BF03016323.

19. Vergouwen MDI, Vermeulen M, van Gijn J, Rinkel GJE, Wijdicks EF, Muizelaar $J P$, et al. Definition of delayed cerebral ischemia after aneurysmal subarachnoid hemorrhage as an outcome event in clinical trials and observational studies: proposal of a multidisciplinary research group. Stroke. 2010;41(10):2391-5. https://doi.org/10.1161/STROKEAHA.110.589275.

20. Dorsch NWC, King MT. A review of cerebral vasospasm in aneurysmal subarachnoid haemorrhage Part I: Incidence and effects. J Clin Neurosci. 1994;1(1):19-26. https://doi.org/10.1016/0967-5868(94)90005-1.

21. Vora YY, Suarez-Almazor M, Steinke DE, Martin ML, Findlay JM. Role of transcranial Doppler monitoring in the diagnosis of cerebral vasospasm after subarachnoid hemorrhage. Neurosurgery. 1999;44(6):1237-47 discussion 1247-8. PMID: 10371622.

22. Sobey CG, Faraci FM. Subarachnoid haemorrhage: what happens to the cerebral arteries? Clin Exp Pharmacol Physiol. 1998;25(11):867-76. https://doi. org/10.1111/j.1440-1681.1998.tb02337.x.

23. Tani E, Matsumoto T. Continuous elevation of intracellular Ca2+ is essential for the development of cerebral vasospasm. Curr Vasc Pharmacol. 2005;2(1): $13-21$.

24. Sloan MA, Haley EC, Kassell NF, Henry ML, Stewart SR, Beskin RR, et al. Sensitivity and specificity of transcranial Doppler ultrasonography in the diagnosis of vasospasm following subarachnoid hemorrhage. Neurology. 1989;39(11):1514-8. https://doi.org/10.1212/WNL.39.11.1514.

25. Lindegaard KF, Nornes H, Bakke SJ, Sorteberg W, Nakstad P. Cerebral vasospasm diagnosis by means of angiography and blood velocity measurements. Acta Neurochir (Wien). 1989;100(1-2):12-24. https://doi. org/10.1007/BF01405268.

26. Sloan MA, Burch CM, Wozniak MA, Rothman MI, Rigamonti D, Permutt T, et al. Transcranial doppler detection of vertebrobasilar vasospasm following subarachnoid hemorrhage. Stroke. 1994;25(11):2187-97. https://doi.org/10.11 61/01.STR.25.11.2187.

27. Sviri GE, Ghodke B, Britz GW, Douville CM, Haynor DR, Mesiwala AH, et al. Transcranial doppler grading criteria for basilar artery vasospasm. Neurosurgery. 2006:59(2):360-5. https://doi.org/10.1227/01.NEU.0000223502.93013.6E.

28. Mascia L, Fedorko L, terBrugge K, Filippini C, Pizzio M, Ranieri VM, et al. The accuracy of transcranial Doppler to detect vasospasm in patients with aneurysmal subarachnoid hemorrhage. Intensive Care Med. 2003;29(7): 1088-94. https://doi.org/10.1007/s00134-003-1780-5.

29. Tsivgoulis G, Sharma VK, Lao AY, Malkoff MD, Alexandrov AV. Validation of transcranial Doppler with computed tomography angiography in acute cerebral ischemia. Stroke. 2007;38(4):1245-9. https://doi.org/10.1161/01.STR. 0000259712.64772 .85 .

30. Razumovsky AY, Gillard JH, Bryan RN, Hanley DF, Oppenheimer SM. TCD MRA and MRI in acute cerebral ischemia. Acta Neurol Scand. 1999;99(1):6576. https://doi.org/10.1111/j.1600-0404.1999.tb00660.x.

31. Baracchini C, Manara R, Ermani M, Meneghetti G. Can TCD be a guiding light? 2000. p. 2942-7.

32. Camerlingo M, Casto L, Censori B, Servalli MC, Ferraro B, Mamoli A. Prognostic use of ultrasonography in acute non-hemorrhagic carotid stroke. Ital J Neurol Sci. 1996;17(3):215-8. https://doi.org/10.1007/BF01995686.

33. Brunser AM, Mansilla E, Hoppe A, Olavarría V, Sujima E, Lavados PM. The Role of TCD in the Evaluation of Acute Stroke. J Neuroimaging. 2016;26(4): 420-5. https://doi.org/10.1111/jon.12334.

34. Lee MT, Piomelli S, Granger S, Miller ST, Harkness S, Brambilla DJ, et al. Stroke Prevention Trial in Sickle Cell Anemia (STOP): Extended follow-up and final results. Blood. 2006;108(3):847-52. https://doi.org/10.1182/blood-2 005-10-009506.
35. Demchuk AM, Christou L, Wein T, Felberg RA, Malkoff M, Grotta JC, et al. Clinical investigative studies. J Neuroimaging. 2000;10(1):1-12. https://doi. org/10.1111/jon20001011.

36. Alexandrov AV, Demchuk AM, Felberg RA, Grotta JC, Krieger DW. Intracranial clot dissolution is associated with embolic signals on transcranial Doppler. J Neuroimaging. 2000;10(1):27-32. https://doi.org/10.1111/jon200010127.

37. Alexandrov AV, Sloan MA, Tegeler CH, Newell DN, Lumsden A, Garami Z, et al. Practice standards for transcranial Doppler (TCD) ultrasound. Part II. clinical indications and expected outcomes. J Neuroimaging. 2012;22(3): 215-24. https://doi.org/10.1111/j.1552-6569.2010.00523.x.

38. Kaspera W, Ładziński P, Larysz P. Transcranial color-coded Doppler assessment of cerebral arteriovenous malformation hemodynamics in patients treated surgically or with stage embolization. Clin Neurol Neurosurg. 2014;116:46-53. https://doi.org/10.1016/j.clineuro.2013.11.001.

39. KasperaW PŁ, Słowiński J, Kopera M, Tomalski W, Slaska-Kaspera A. Blood flow velocity in the arteries of the anterior cerebral artery complex in patients with an azygos anterior cerebral artery aneurysm: a trans- cranial color-coded sonography study. Clin Neurol Neurosurg. 2009;111(1):63-8. https://doi.org/10.1016/j.clineuro.2008.08.007.

40. Bartels E. Evaluation of arteriovenous malformations (AVMs) with transcrania color-coded duplex sonography: does the location of an AVM influence its sonographic detection. J Ultrasound Med. 2005;24(11):1511-7. https://doi. org/10.7863/jum.2005.24.11.1511.

41. Hashimoto T, Young WL, Prohovnik I, Gupta DK, Ostapkovich ND, Ornstein E. Increased cerebral blood flow after brain arteriovenous malformation resection is substantially independent of changes in cardiac output. J Neurosurg Anesthesiol. 2002;14(3):204-8. https://doi.org/10.1097/00008506-200207000-00005.

42. Tyagi SK, Mahapatra AK, Mishra NK. Transcranial Doppler evaluation of blood flow velocity changes in basal cerebral arteries in cerebral AVMs following embolization and surgery. Neurol India. 2000;48(2):112-5.

43. Jo K, Kim J, Hong S, et al. Hemodynamic changes in arteriovenous malformations after radiosurgery: transcranial Doppler evaluation. World Neurosurg. 2012;77(2):316-21. https://doi.org/10.1016/j.wneu.2011.06.061.

44. Guo HH, Pan YH, Zhou LF, Shi YQ. Research on hemodynamics of cerebral arteriovenous malformation by Doppler ultrasound. Chin Med J (Engl). 1993; 106(5):351-6.

45. Diehl RR, Henkes $H$, Nahser HC, Kuhne D, Berlit P. Blood flow velocity and vasomotor reactivity in patients with arteriovenous malformations: A transcranial doppler study. Stroke. 1994;25(8):1574-80. https://doi.org/10.11 61/01.STR.25.8.1574.

46. Park SH, Hwang SK. Transcranial Doppler study of cerebral arteriovenous malformations after gamma knife radiosurgery. J Clin Neurosci. 2009;16(3): 378-84. https://doi.org/10.1016/j.jocn.2008.04.025.

47. Nicoletto HA, Burkman MH. Transcranial Doppler series part II: Performing a transcranial Doppler. Am J Electroneurodiagnostic Technol. 2009;49(1):1427. https://doi.org/10.1080/1086508X.2009.11079700.

48. Soustiel JF, Shik V, Feinsod M. Basilar vasospasm following spontaneous and traumatic subarachnoid haemorrhage: Clinical implications. Acta Neurochir (Wien). 2002;144(2):137-44. https://doi.org/10.1007/s007010200016.

49. NarayanRK, Michel ME, Ansell B, Baethmann A, Biegon A, Bracken MB, BullockMR, Choi SC, Clifton GL, Contant CF, Coplin WM, Dietrich WD, GhajarJ, Grady SM, Grossman RG, Hall ED, Heetderks W, Hovda DA, Jallo J,Katz RL, Knoller N, Kochanek PM, Maas Al, Majde J, Marion DW,Marmarou A, Marshall LF, Mclntosh TK, Miller E, Mohberg N, MuizelaarJP, Pitts LH, Quinn P, Riesenfeld G, Robertson CS, Strauss KI,Teasdale G, Temkin N, Tuma R, Wade C, Walker MD, Weinrich M, Whyte J,Wilberger J, Young AB, Yurkewicz L. Clinical trials in head injury. JNeurotrauma. 2002;19(5):503-57. https://doi.org/10.1089/089771502753754037.

50. Masel BE, DeWitt DS. Traumatic brain injury: a disease process, not an event. J Neurotrauma. 2010;27(8):1529-40. https://doi.org/10.1089/neu.2010.1358.

51. MckeeAC, Daneshvar DH. The neuropathology of traumatic brain injury. HandbClin Neurol. 2015;127:45-66. https://doi.org/10.1016/B978-0-444-52892-6. 00004-0.

52. Kwasnica C, Brown AW, Elovic EP, Kothari S, Flanagan SR. Congenital and Acquired Brain Injury. 3. Spectrum of the Acquired Brain Injury Population. Arch Phys Med Rehabil. 2008;89(3 SUPPL. 1):15-20.

53. Ogasawara K, Inoue T, Kobayashi M, Endo H, Yoshida K, Fukuda T, et al. Cerebral hyperperfusion following carotid endarterectomy: diagnostic utility of intraoperative transcranial Doppler ultrasonography compared with single-photon emission computed tomography study. AJNR Am J Neuroradiol. 2005;26(2):252-7. 15709121. 
54. De Borst GJ, Moll FL, Van de Pavoordt HDWM, Mauser HW, Kelder JC, Ackerstaf RGA. Stroke from carotid endarterectomy: When and how to reduce perioperative stroke rate? Eur J Vasc Endovasc Surg. 2001;21(6):4849. https://doi.org/10.1053/ejvs.2001.1360.

55. Doig D, Turner EL, Dobson J, Featherstone RL, De Borst GJ, Stansby G, et al. Risk factors for stroke, myocardial infarction, or death following carotid endarterectomy: results from the international carotid stenting study. Eur J Vasc Endovasc Surg. 2015;50(6):688-94. https://doi.org/10.1016/j.ejvs.2015.08.006.

56. Pennekamp CWA, Tromp SC, Ackerstaff RGA, Bots ML, Immink RV, Spiering $W$, et al. Prediction of cerebral hyperperfusion after carotid endarterectomy with transcranial Doppler. Eur J Vasc Endovasc Surg. 2012;43(4):371-6.

57. Van Mook WNKA, Rennenberg RJMW, Schurink GW, Van Oostenbrugge RJ, Mess WH, Hofman PAM, et al. Cerebral hyperperfusion syndrome. Lancet Neurol. 2005;4(12):877-88. https://doi.org/10.1016/S1474-4422(05)70251-9.

58. Zurynski Y, Dorsch N, Pearson I, Choong R. Transcranial Doppler ultrasound in brain death:experience in 140 patients. Neurol Res. 1991;13(4):248-52. https://doi.org/10.1080/01616412.1991.11740000 PMID: 1687335.

59. Conti A, lacopino DG, Spada A. Transcranial Doppler ultrasonography in the assessment of cerebral circulation arrest: improving sensitivity by transcervical and transorbital carotid insonation and serial examinations. Neurocrit Care. 2009;10(3):326-35. https:/doi.org/10.1007/s12028-009-9199-7.

60. Koc RK, Selcuklu A, Meral M, Menku A, Tumturk F. The role of transcranial Doppler in the confirmation of brain death. Turk Neurosurg. 1997;7(1-2):9-12.

61. Bogdahn U, Becker G, Frohlich T. Contrast- enhanced transcranial colorcoded real-time sonography allows detection of primary central nervous system tumor vascularisation. Radiology. 1994;192(1):141-8. https://doi.org/1 0.1148/radiology.192.1.8208926.

62. Becker G, Becker T, Struck M. Reduced echogenicity of brainstem raphe specific to unipolar depression: a transcranial color-coded real-time sonography study. Bioi Psychiatry. 1995;38(3):180-4. https://doi.org/10.1016/ 0006-3223(94)00263-3.

63. Becker G, Struck U, Bogdahn U, Becker T. Echogenicity of the brainstem raphe in patients with major depression. Psychiatry Res. 1994;55(2):75-8. https://doi.org/10.1016/0925-4927(94)90002-7.

64. Ram Z, Walbridge S, Shawker T, Culver KW, Blaese RM, Oldfield EH. The effect of thymidine kinase trans- duction and ganciclovir therapy on tumor vasculature and growth of 9L gliomas in rats. J Neurosurg. 1994;81(2):25660. https://doi.org/10.3171/jns.1994.81.2.0256.

\section{Publisher's Note}

Springer Nature remains neutral with regard to jurisdictional claims in published maps and institutional affiliations.

\section{Submit your manuscript to a SpringerOpen ${ }^{\circ}$ journal and benefit from:}

- Convenient online submission

- Rigorous peer review

- Open access: articles freely available online

- High visibility within the field

- Retaining the copyright to your article

Submit your next manuscript at $\boldsymbol{\nabla}$ springeropen.com 